\title{
Pure Lateral Traumatic Dislocation of Elbow: Case Report of a Rare Entity
} Ismail Kabbaj $^{1 *}$, Mohamed Reda Fekhaoui ${ }^{1}$, Ayoub Mjidila ${ }^{1}$, Jalal Mekkaoui ${ }^{1}$, Reda-Allah Bassir ${ }^{1}$, Moncef Boufettal $^{1}$, Mohamed Kharmaz ${ }^{1}$, Moulay Omar Lamrani ${ }^{1}$, Mohamed Saleh Berrada ${ }^{1}$

${ }^{1}$ Orthopedic Surgery Department of Ibn Sina Hospital, University Mohamed V, Rabat 10100, Morocco

DOI: $10.36347 /$ sjams.2021.v09i04.015

| Received: 05.03.2021 | Accepted: 12.04.2021 | Published: 15.04.2021

*Corresponding author: Ismail Kabbaj

Abstract

The elbow is the 2nd joint most affected by dislocations. These often occur in a traumatic context and particularly during sport's accidents. Lateral elbow dislocation is a rare form of this type of injury, and its pure form is exceptional and rarely reported in the literature. We report the observation of a pure lateral dislocation of the elbow in a young athlete (Judoka) aged 31. The reduction was performed urgently under general anesthesia. Immobilization by plaster splint was performed for two weeks, followed by rehabilitation. The functional results were very satisfactory with a follow-up of 8 months.

Keywords: Lateral dislocation; Elbow joint; Sport accident; Reduction.

Copyright $(\odot) 2021$ The Author(s): This is an open-access article distributed under the terms of the Creative Commons Attribution 4.0 International License (CC BY-NC 4.0) which permits unrestricted use, distribution, and reproduction in any medium for non-commercial use provided the original author and source are credited.

\section{INTRODUCTION}

The elbow joint is an inherently stable joint, but its dislocation is very common. The majority of these dislocations are posterolateral or posterior. Traumatic lateral elbow dislocation is rare and is usually associated with fractures, severe soft tissue damage, and or neurovascular damage. Pure lateral dislocation is therefore exceptional, and its reduction is very difficult without anesthesia or muscle relaxation. We report the case of a 31-year-old athlete who presented with pure closed lateral dislocation of the right elbow, following a sport's accident, and reduced closed under general anesthesia. We will thus underline the importance of a rapid closed reduction of the dislocation and an early mobilization to ensure good functional results.

\section{CASE RePORT}

We report the case of a 31-year-old athletic young adult, with no particular pathological history, who presented four hours after his trauma to the emergency room following a sports accident, while practicing judo, where the patient had dropped during training on the palmar face of the right hand, elbow extended. On clinical examination, the patient was in the posture of the traumatized upper limb, with a deformed, widened, semi-flexed right elbow with a lateral translation of the entire forearm, which was in pronation (Figure 1 and 2). The olecranon was palpable in a lateral situation with a disappearance of the relief of the external condyle and a subcutaneous prominence of the trochlea. Palpation and mobilization of the elbow were painful. There was no skin opening, the nervous examination was normal, motor and sensory, and the pulses were present. AP and lateral elbow radiographs showed lateral dislocation of the right elbow with lateral translation of the ulna in the plane of the humeral paddle, without any associated fracture (Figure 3 and 4). The patient was taken to the operating room where an orthopedic reduction by external maneuvers, under general anesthesia was performed. The elbow was first de-impacted by applying longitudinal traction to the forearm with counter-traction to the arm. Light medial pressure was then applied to the olecranon, until a reductional click was felt. The instability in valgus and varus of the elbow was verified in full extension and 30 ${ }^{\circ}$ of flexion. The elbow was subsequently immobilized in a cast splint with a $90^{\circ}$ elbow flexion for two weeks. Follow-up X-rays confirmed good congruence of the elbow joint, indicating reduction of the dislocation (Figure 5). After two weeks, the splint was removed, and active physiotherapy-type rehabilitation was started. At the last 8-month check-up, functional recovery was very satisfactory and the elbow was stable. The patient was thus able to restart his sports activity. 


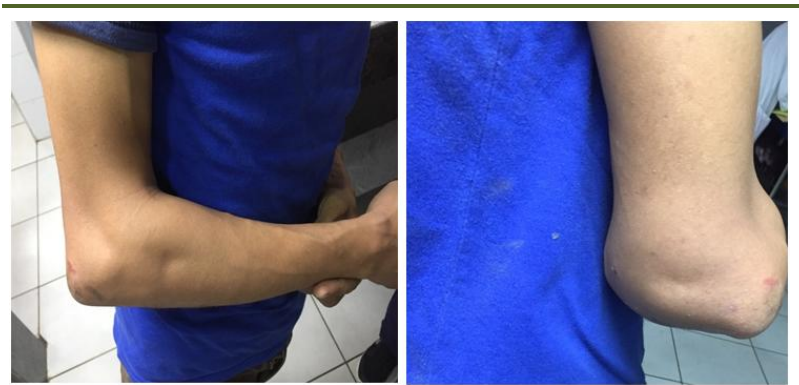

Fig-1 and 2: Clinical picture of the deformity of the right elbow

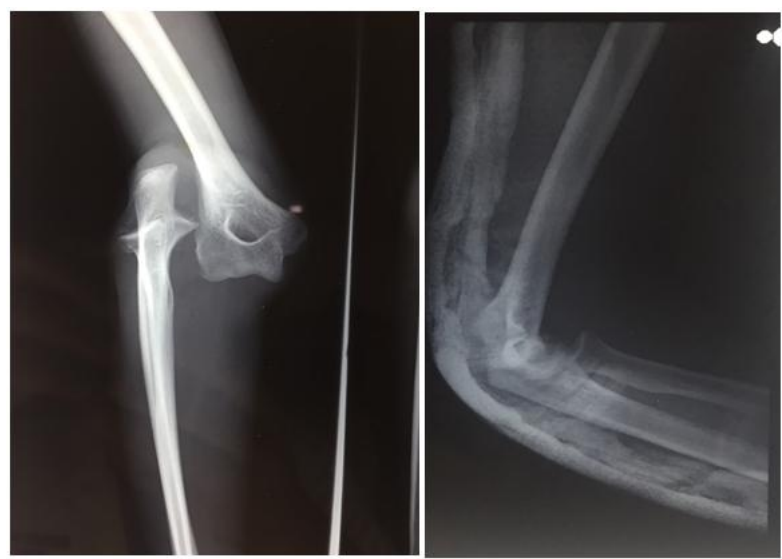

Fig-3 and 4: Anteroposterior and lateral view of the pure lateral dislocation of the right elbow

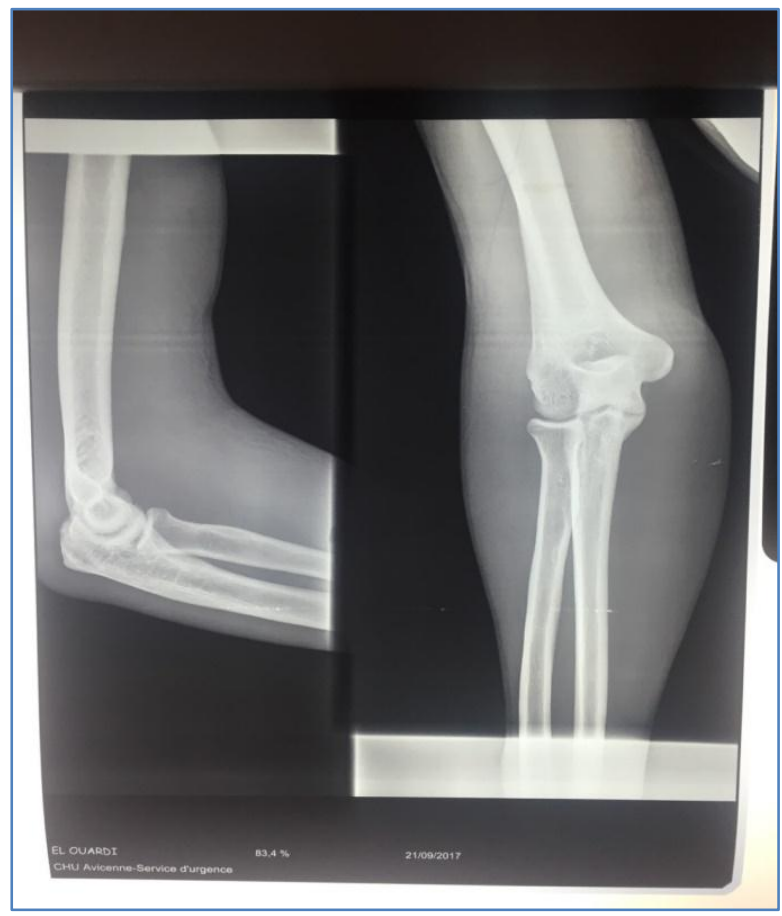

Fig-5: Anteroposterior and lateral view of the pure lateral dislocation of the right elbow after reduction

\section{DisCUSSION}

Pure lateral elbow dislocation is a very rare entity, although it has been known for over two centuries [1]. It consists of a dislocation in the transverse plane without an antero-posterior element, which differentiates it from the postero-lateral dislocation. However, several authors include lateral dislocations in variants of posterolateral dislocations of the elbow [2]. According to Speed [3], lateral displacement may be incomplete (Type I), omplete with the forearm supinated (Type II) or pronated (Type III). The mechanisms reported in lateral elbow dislocations are indirect (fall with an elbow extended) or direct (impact on the medial aspect of the proximal ends of the forearm bones) [4]. In our case, it was a direct trauma (Type III).

In case of lateral elbow dislocation due to severe capsuloligamentous injury, reduction can be easily achieved. However, reduction of these fractures is sometimes difficult due to various factors such as swelling, concomitant injury or the interposition of bony structures [5] or soft tissues. The irreducibility in this case may be due to either the embedding of the brachialis muscle [6] or the anconeus muscle which moves into the trochlear notch preventing reduction [7]. Open reduction is necessary in these cases. The nerve damage found in the literature most often concerns the ulnar nerve (6 to $20 \%$ of cases depending on the series) $[8,9]$ or median [9]. Damage to the radial nerve is exceptional.

Different techniques have been described for the reduction of lateral elbow dislocations. They all have in common the application of two major traction forces along the axes of the humerus and forearm. Levine described in 1953 reducing an elbow dislocation by having the patient sit in a chair with the arm hanging over the back of the chair. But this technique requires the cooperation of the patient, which is not always easy to obtain [10]. Parwin used a technique of placing the patient on a high table in a supine position, gently pulling down on the wrist for a few minutes, and lifting the humerus laterally to complete the reduction [11].

Meyn and Quigley described reduction of the posterior elbow dislocation with a technique that involved pulling on the hanging arm and grasping the olecranon with the operator's other hand [12]. Stimson described a technique, which consists in placing the patient in a supine position on a table with the arm hanging down, on which we apply weights. This technique was subsequently modified by adding a second person to guide the olecranon in a purely medial direction. The effect of muscle relaxation and gravity, helps reduce dislocation [13].

\section{Conclusion}

Pure lateral dislocation of the elbow joint is a very rare type of dislocation and is often secondary to high energy trauma. It can be associated with severe ligament damage around the elbow, which is responsible for the irreducibility of the dislocation requiring open reduction. In all cases, immobilization of the elbow must be of short duration and rehabilitation 
must be started as soon as possible in order to avoid stiffness of the elbow.

\section{REFERENCES}

1. Desault PJ, Bichat XE, Roux PJ. Oeuvres chirurgicales ou exposé de la doctrine et de la pratique de P.-J. Desault,chirurgien en chef du Grand Hospice d'Humanité de Paris,v.1 (French Edition). Nabu Press; 2011

2. Bucholz RW, Heckman JD, Tornetta P. Rockwood and Green's fractures in adults.Lippincott Williams \&Wilkins. 2010, 2059

3. Speed K. A text-book of fractures and dislocations covering their pathology. Diagnosis and treatment. Ed. rev.ed. Philadelphia: Lea; 1935, 1000.

4. Latifi M, Aziz S, Alaoui A,Essadki B, Fikry T.Lateral dislocation of the elbow: pathophysiological and therapeutic analysis.Rev Chir Orthop Repar Appar Mot. 2003;89(5):453-6.

5. Vijaya S. Lateral dislocation of the elbow joint. Singapore Med J 1966;7; 139-41

6. Smith MI. Surgery of the elbow. Springfield, Illinois: Charles C Thomas; 1954: 233-234
7. Exarchou EJ.Lateral dislocation of the elbow. Acta Orthop Scand. 1977;48:161-3 15

8. Pritchard DJ, Linscheid RL, Svien HJ. Intraarticular median nerve entrapment with dislocation of the elbow. Clin Orthop. 1973;90:100-3

9. Fourrier P, Levai JP, Collin JP. Incarcération du nerf médian au cours d'une luxation du coude. Rev Chir Orthop. 1977;63:13-6

10. Lavine LS. A simple method of reducing dislocations of the elbow joint. J Bone Joint Surg Am. 1953 Jul;35-A(3):785-786.

11. Parvin RW. Closed reduction of common shoulder and elbow dislocations without anesthesia. AMA Arch Surg. 1957 Dec;75(6):972-975.

12. Meyn MA, Quigley TB. Reduction of posterior dislocation of the elbow by traction on the dangling arm. Clin Orthop Rel Res. 1974;106-108.

13. Khan SK, Chopra R, Chakravarty D. Successful closed manipulation of a pure lateral traumatic dislocation of the elbow joint using a modified Stimson's technique: a case report. J Med Case Rep. 2008;2(2):170. 